\title{
Compositional variation of Large Igneous Provinces moderated by water in mantle plumes
}

\author{
HAO SUN ${ }^{1}$, JiA LIU*1, QUNKE XIA ${ }^{1}$, EERO HANSKI ${ }^{2}$ \\ ${ }^{1}$ Key Laboratory of Geoscience Big Data and Deep Resource \\ of Zhejiang Province, School of Earth Sciences, Zhejiang \\ University, Hangzhou, China \\ sunhao94@zju.edu.cn, liujia08@ustc.edu.cn, \\ qkxia@zju.edu.cn \\ 2 Oulu Mining School, University of Oulu, Finland. \\ eero.hanski@,oulu.fi
}

Trace amount of water can play significant role in modifying many physical and chemical characteristics of the mantle. However, knowledge about the water reservoir in the deep mantle is not so clear. The recent investigations on the Archaeon komatiites ${ }^{1,2}$ shows that in the deep mantle there is a water-rich reservoir, with much higher water content than any sources of mid-ocean ridge basalts and ocean island basalts.

The Large igneous provinces (LIPs) are known for their rapid production of enormous volumes of magma, which has been generally suggested to be associated with the mantle plumes. However, how their long-recognized division into low-Ti and high-Ti magma types on local and regional scales, a distinction that basically related to the dynamics of the responsible mantle plume, linked with the compositional heterogeneity of the plume (e.g. recycled eclogite-bearing and variably hydrated) is poorly constrained by observations. Here, we present that the high- and low-Ti division of the primary magmas are closely correlated with the water contents of the upwelling plume. The model suggests that the sharp variation in the chemical composition for the primary magma of LIPs in both local and regional scale, could be mainly explained by the commentary role of the recycled eclogite and hydrated components in the mantle plume, without requiring the catastrophic thinning of the lithospheric mantle. Our model thus implies the significant role of water from the deep earth on the chemistry of surface giant volcanisms.

1. Sobolev, A. V. et al. Komatiites reveal a hydrous Archaean deep-mantle reservoir. Nature 531, 628632 (2016).

2. Sobolev, A. V. et al. Deep hydrous mantle reservoir provides evidence for crustal recycling before 3.3 billion years ago. Nature 571, 555-559 (2019). 